\title{
Imagem corporal e envelhecimento: Vicissitudes de uma tragédia moderna
}

\author{
Body image and aging: Vicissitudes of a modern tragedy
}

Jacqueline de Oliveira Moreira

\begin{abstract}
Doutora em Psicologia Clínica pela Pontifícia Universidade Católica de São Paulo (PUC-SP), professora do mestrado e doutorado em Psicologia Pontifícia Universidade Católica de Minas Gerais (PUC Minas), Belo Horizonte, MG - Brasil, e-mail: jackdrawin@yahoo.com.br
\end{abstract}

Recebido: 22/12/2010 Received: 12/22/2010

Aprovado: 17/03/2011

Approved: 03/17/2011

\section{Resumo}

0 presente artigo visa a articulação da perspectiva que anuncia um horror à imagem de envelhecimento do corpo com os ideais sociais de juventude eterna e os apelos das tecnologias biomédicas por cirurgias plásticas. Sabemos que o envelhecimento do ser humano pode ser diferenciado segundo vários conceitos: cronológico, biológico, social e psicológico. Assim, o envelhecimento do corpo, também é determinado por fatores físicos, psíquicos e sociais. Não negamos a objetividade do envelhecimento corporal, mas não podemos negar as influências psíquicas e sociais na percepção desse corpo que envelhece. Assim, buscamos situar algumas posições sobre "corpo" e trabalhar a tragédia moderna, que acredita na vontade e na liberdade da ação para se contrapor ao envelhecimento do corpo.

Palavras-chave: Idoso. Imagem corporal. Pós-modernidade.

\section{Abstract}

This article aims to articulate the perspective which indicates horror as a reaction to the aging body, the social ideal of eternal youth, and the appeal of biomedical techniques for plastic surgery. We know that human aging can be distinguished according to various concepts: chronological, biological, social and psychological. Thus, the aging of the body is also determined by physical, psychic and social factors. We do not deny the objectivity of the aging of the body. We cannot, however, deny the psychic and social influences over the perception of the aging body. In this sense, we aim to establish certain points regarding "the body", and to discuss the modern tragedy, which believes in will and freedom of action to counterbalance the aging of the body.

Keywords: Elderly persons. Body image. Post-modernity. 


\section{Introdução}

O envelhecimento é um destino humano, mas não podemos negar que fatores sociais e psíquicos atravessam esse processo. 0 envelhecimento do ser humano pode ser diferenciado segundo vários conceitos: cronológico, biológico, social e psicológico. A idade cronológica é marcada pela data de nascimento. A Organização das Nações Unidas (ONU) considera como idoso, em países desenvolvidos, a pessoa com mais de 65 anos, e em países em desenvolvimento, a pessoa com mais de 60 anos. A idade biológica é determinada pela herança genética e pelo ambiente, e se refere às mudanças fisiológicas, anatômicas, hormonais e bioquímicas. A idade social relaciona-se às normas, crenças e ideais sociais. Nossos comportamentos apresentam um padrão comum; por exemplo, parece existir uma idade esperada para o casamento. A sociedade tem a expectativa de que entre os 26 e os 36 anos as pessoas irão se casar. Podemos pensar em um "relógio social". A idade psicológica refere-se aos posicionamentos subjetivos e aos recursos psíquicos que os indivíduos apresentam para lidar com os eventos da vida nos seus diferentes momentos.

Mesmo que a idade cronológica seja um indicador um tanto impreciso para determinar o envelhecimento, visto que é um processo biológico, social e psicológico, ainda assim é o critério para determinar as categorias etárias. Devemos, no entanto, pensar a idade cronológica como uma referência, e não um absoluto. Nenhuma disciplina científica acredita que a idade cronológica cause o desenvolvimento ou envelhecimento. "A idade cronológica pode ser um organizador, mas não a referência fundamental para pensar o processo do desenvolvimento humano" (Neri, 2001, p. 22).

Assim, o envelhecimento do corpo é, também, determinado por fatores físicos, psíquicos e sociais. Não negamos a objetividade do envelhecimento corporal, mas também não podemos negar as influências psíquicas e sociais envolvidas na percepção desse corpo que envelhece. 0 encontro com nosso corpo a partir do espelho reflete o corpo objetivo revestido de desejos, fantasias, ideais individuais e sociais. Somos seres sociais, e por esse fato as posições sociais modificam nossa visão. Sabemos que, para alguns autores da Psicanálise, como Dolto (1984), o conceito de imagem corporal é decisivo, e ele ocupa um lugar central na psicomotricidade, mas não pretendemos realizar uma exegese desse conceito. Nosso objetivo é mais humilde: pensar de que forma a imagem do envelhecimento denunciada pelo corpo com rugas causa incômodo na sociedade contemporânea, e leva ao aumento de cirurgia plástica que camufla as marcas do tempo.

\section{0 idoso na passagem do tempo}

O envelhecimento é percebido de maneira diferente ao longo da história da humanidade. 0 homem sempre guardou certo horror à velhice, por associá-la à morte. Todavia as organizações sociais holistas reservam aos idosos o lugar de guardiões da tradição. Alguns autores (Dumont, 1985; Giddens, 1997) denominam holistas ou tradicionais as sociedades pré-modernas, e nesse modelo o idoso pode ser o guardião da sabedoria que deve ser transmitida aos mais jovens (Mascaro, 2004).

Sabemos que a passagem da pré-modernidade para a modernidade é marcada pela ruptura com as tradições. Segundo Renaut (1998, p. 31), o traço mais específico das sociedades modernas é a "contínua dissolução das referências oriundas do passado". O homem pré-moderno voltava-se para seu passado, encontrava nele uma referência normativa para seu presente. A modernidade opera uma ruptura com a tradição, e "os valores do passado parecem estar singularmente enfraquecidos em benefício da celebração do presente e do novo" (Renaut, 1998, p. 36). Segundo Drawin (2003), o homem moderno voltava-se para o futuro e buscava nele as referências normativas de sua vida. O desenvolvimento da ciência moderna produz nos sujeitos uma aposta no futuro. Assim o homem pré-moderno e o moderno situam-se na trama temporal da história, na certeza do movimento limitador do tempo. A pós-modernidade é caracterizada pela ruptura, pelo desrespeito ao vínculo temporal com o passado e/ou com o futuro. Vive-se a imediaticidade do agora. Não há história, pois não importa o passado ou o futuro. 0 presente adquire uma dimensão tirânica e perversa. O futuro deixou de ser uma aposta, o passado não é respeitado como referencial; só resta a vacuidade do presente. Deixamos de nos reconhecer na obrigação de viver para outra coisa que não nós mesmos. Parafraseando Santo Agostinho, podemos perguntar: o que é a história, se o passado já não existe como referência, o futuro ainda não existe e deixou de ser aposta, e o presente se esvai a cada segundo?

A questão do tempo habita o cerne da experiência subjetiva, representa um marco na constituição da subjetividade, e por isso é tema crucial para as reflexões sobre as formas subjetivas de envelhecimento. 
Pensamos que pode haver uma articulação entre a valorização do tempo do presente na atualidade e o domínio do desejo de manutenção da juventude. A juventude é exatamente o momento do presente, pois se rompe com o passado, representado pela família, e se lança em uma ilusão de imortalidade e onipotência que não percebe o futuro como um limite. 0 jovem vive intensamente o hoje e recusa a passagem do tempo.

Segundo Lasch (1983), uma das características do mundo moderno é o horror à velhice. A cultura pós-moderna apresenta um explícito horror à velhice, fato que produz nos sujeitos uma dificuldade em assumir o envelhecimento e seus signos como, por exemplo, o envelhecimento do corpo. É importante ressaltar que o Eu não envelhece: com o tempo, adquire mais experiências. Mas o corpo envelhece. É preciso pensar sobre o estilo de vida, a posição diante dos eventos de vida, e sobre como trabalhar os sentimentos, afetos, fantasias, imaginário e recursos psíquicos para se viver bem a velhice.

Não podemos negar o corpo do idoso, e é preciso assumir que essa realidade é produto da interação entre a objetividade, a subjetividade e a sociedade. Como vivemos em uma cultura de horror à velhice, o corpo marcado pelas rugas deve ser evitado a qualquer preço. $\mathrm{E}$ as tecnologias médicas se encontram atentas a essa demanda. As ofertas se multiplicam: botox, cirurgias, laser, fios de ouro. Segundo Le Breton (2003, p. 28), "o corpo constitui um alter/ ego, um duplo, um outro si mesmo, mas disponível a todas as modificações, prova radical e modulável da existência pessoal e exibição de identidade escolhida provisória ou duravelmente". Podemos citar como exemplo as cirurgias plásticas, que buscam a semelhança do sujeito com um ideal, que pode ser uma boneca, um animal ou um ator famoso. A cirurgia se presta à realização de fantasias, e o cirurgião, assim como um profissional da alta costura, cria uma infinidade de roupas para renovar o look. Nesse caso, o corpo é um rascunho que precisa ser melhorando para se alcançar o ideal desejado.

No envelhecimento, as mudanças corporais se apresentam como explicitação dos movimentos temporais. 0 tempo se expressa a partir do corpo, oferecendo-nos uma possibilidade de significação histórica. Corpo e tempo se entrecruzam no devir da existência. Assim, corpo, psíquico, tempo e finitude se enlaçam no desenrolar histórico da existência. Os limites espaciais e temporais de uma existência são oferecidos pelo corpo. É o corpo que ocupa um lugar no espaço e, portanto, está submetido à Lei de Newton que diz que dois corpos não ocupam o mesmo lugar ao mesmo tempo. Assim, nosso eu é, antes de tudo, corporal. Não é possível separar corpo de psiquismo, corpo de temporalidade, corpo de espaço e, por conseguinte, corpo de existência. Mas, em diferentes momentos da história da humanidade, o corpo foi estudado como uma condenação, ou como uma chave de abertura para a verdade do universo e outras versões. Foucault (1996), na sua genealogia sobre o sujeito, revela que o corpo foi o alvo, o objeto de dominação. Essa perspectiva é constantemente direcionada para o desenvolvimento daquilo que se configurou como sendo a microfísica do poder, ou seja, o foco na corporeidade de cada indivíduo - com seus hábitos, instintos, pulsões, sentimentos, emoções, impulsos e vicissitudes - como o ponto fundamental sobre o qual atua um emaranhado complexo de uma série de lutas e de confrontos inerentes a tais saberes, no processo de produção de poder. Assim, as diferentes posições em relação ao corpo, ao longo da história, podem se vincular às perspectivas em relação ao envelhecimento humano.

\section{Corpo na história: Horror ao corpo envelhecido}

O conceito de corpo é interpenetrado de história e se articula com diferentes contextos discursivos. O corpo na Grécia, por exemplo, foi glorificado na arte, mas era considerado a prisão da alma. Não podemos deixar de mencionar que o corpo glorificado na arte é o corpo jovem, ideal de beleza. E, nessa perspectiva, na medida em que o corpo envelhece, aumentam os ferros da prisão. Assim, o ancião ocupa um lugar de sabedoria, mas seu corpo não é alvo de contemplação estética.

Na Idade Média, a ideia do corpo como uma prisão da alma é lapidada, pois o corpo é carcereiro e corruptor. Segundo Bezerra (1989, p. 220), na Idade Média, "o homem é levado a um permanente esforço de observação, exame e autodiscernimento para diferenciar o que - vindo do interior da alma significa impulso sexual, tentação, ou vontade racional, livre-arbítrio". 0 corpo é o palco do demoníaco, campo dos prazeres inferiores, e porta em si o peso dos pecados. É preciso punir o corpo para alcançar a salvação da alma. Nesse sentido, o corpo jovem é mais perigoso, pois possui mais apelo de sedução. É preciso esconder o corpo e a juventude. 
No mundo moderno, o interesse pelo corpo caminha mais próximo da busca de dominação, controle, sujeição e investigação científica. Nenhum fato positivo deve escapar do crivo da Ciência. Com a crise da perspectiva transcendente, na forma como é apresentada pela Igreja da Idade Média, resta a crença no materialismo e um refluxo para a subjetividade. $0 \mathrm{eu}$ passa a ocupar um lugar central, de senhor da natureza e, inclusive, de senhor do próprio corpo. 0 corpo humano passa a ser considerado um objeto entre outros e deve ser alvo da pesquisa científica. Nesse caso, o interesse é maior sobre o corpo da criança, na tentativa de se decifrar os enigmas do desenvolvimento. A velhice é pensada como momento de declínio do desenvolvimento. Assim, o corpo do idoso tem pouco a oferecer sobre a vida.

Parece importante ressaltar que o sentimento de individualidade que os historiadores identificam como a emergência do eu no século XVIII irá, a partir da segunda metade do século XX, privilegiar a identidade corporal. Assistiremos, no mundo contemporâneo, a uma identificação do indivíduo com seu corpo.

Assim, em nossa cultura atual, o corpo goza de lugar privilegiado. Mas como definir corpo? A definição de um conceito depende, primeiramente, do método utilizado para abordá-lo. Podemos pensar o corpo seguindo uma lógica formal: o corpo como dado objetivo, atributo concreto. Ele, então, pode ser entendido como um conjunto de sistemas, aparelhos, órgãos que obedecem a funções específicas, superiores (pensamento) ou inferiores (arco reflexo) e que formam um indivíduo.

Essa perspectiva parece-nos essencialista; o corpo como substrato, como dado empírico. Sem negar essa posição, podemos pensar o corpo de maneira dialética, relacional. Ele é um construto humano que tem sua origem na relação com o outro (mãe). O corpo pode ser pensando, pela lógica simbólica, como um elemento dentro de um conjunto. Nesse sentido, interessa o lugar ou posição que o corpo ocupa dentro de uma estrutura. Anorexia, por exemplo, pode ser pensada dentro da relação entre quatro categorias: corpo, imagem corporal, alimento e ideal social. Na Idade Média, o ideal social é o de purificação da alma, libertação dos pecados do corpo para alcançar o divino. Assim, um quadro de anorexia responde ao ideal de desprendimento da vida material. No mundo pós-moderno, o ideal social é o da beleza magra.
0 método fenomenológico (Merleau-Ponty, 1945/1994) oferece-nos outro caminho para pensar o corpo, a partir da consciência do próprio corpo, uma experiência vivencial do corpo. Temos a posição metafísica (Schopenhauer, 1819), que pensa o corpo como chave e abertura para a verdade metafísica da Vontade Una, Absoluta, e princípio de todas as coisas.

Falar de corpo em Psicologia é dizer de uma unidade indivisível, integrada, síntese e sede das funções físicas (dos órgãos, aparelhos e sistemas vitais) e das funções psíquicas (cognitivas, volitivas e afetivas), compreendendo os modos de relações interpessoais, sentimentos, humor. 0 corpo é, portanto, uma entidade que suporta todo o conjunto de sistemas, aparelhos e órgãos que responde a funções físicas e psíquicas, mas o corpo também é uma realidade visual.

É interessante pensar por que o corpo se tornou um objeto de estudo de diferentes campos do saber, como a Psicologia, a Psicanálise, a História e a Antropologia. Pois a tradição filosófica cartesiana atribuía ao corpo um lugar secundário (Courtine, Corbin \& Vigarello, 2008). Quais as modificações ocorridas na tradição racionalista cartesiana para que hoje possamos pensar o corpo como indissociável do sujeito? Segundo Courtine et al. (2008) o corpo foi inventando teoricamente no século XX, e seria Freud o grande responsável por sua nova percepção. A teoria freudiana propõe pensar o corpo para além da carnalidade. 0 corpo não é apenas um organismo biológico. Ele é atravessado pela linguagem, e esta, por sua vez, causa a existência do corpo fora da pura sensação carnal.

Assim, o corpo e a imagem corporal são fontes de interesse de diversos saberes, mas não podemos deixar de mencionar a concepção de corpo no interior da proposta freudiana. Freud (1895/1976b) constrói um vocabulário específico para trabalhar com a noção de corpo. Ele se ocupa do corpo situando-o para além do aparato biológico. Freud, ao apropriar-se do corpo humano, aponta e reconhece a existência de duas dimensões: o ponto de partida do neurologista é o corpo em sua dimensão anatômica/biológica que podemos definir como Corpo Bio, marcado pela presença de instintos que visam a satisfazer suas necessidades. A novidade freudiana, porém, é o corpo pensado em sua dimensão pulsional/representacional - definindo como Corpo Psíquico, regido pela lei do desejo e movido pela energia pulsional. 
Assim Freud (1895/1976a) afirma que o corpo possui excitações internas que não podem, por si, encontrar supressão. 0 organismo humano, segundo Freud (1895/1976a), é incapaz de promover uma ação específica, podendo esta apenas ser efetuada por meio de ajuda alheia.

Freud (1895/1976b), analisando suas pacientes histéricas, reconheceu que os sintomas apresentados por elas mostravam-se como estruturas de linguagem inscritas no corpo, as quais eram passíveis de decifração. Nesse sentido, Freud situou que, na origem dos sintomas, havia fantasias de ordem sexual, afirmando que o corpo tratado pela psicanálise refere-se a um corpo possuidor de dimensões erógenas, e que por sua vez experimenta satisfações autoeróticas.

Assim, ainda que Freud (1895/1976a) tenha se apoiado em bases fisiológicas - admitindo, a priori, que o corpo era uma simples dotação neuroanatômica que possuía descargas motoras que produziam resultados aliviantes para os instintos - postula, a posteriori, a emergência de um corpo erógeno que se faz presente na psicopatologia do cotidiano. Dessa maneira, a teoria freudiana privilegia a natureza essencialmente erógena do corpo, sendo esta regida pela lei do desejo, a qual tem por finalidade a busca de satisfação pulsional. Segundo Elia (1995, p. 96), "o corpo só poderá ser pensado pulsionalmente como corpo-efeito do investimento libidinal".

Encontramos, na teoria freudiana, diferentes reflexões sobre o corpo. Nesse momento, interessa-nos a articulação entre corpo e a noção de eu: se o corpo possibilita a percepção do eu, quais são as possíveis consequências do envelhecimento do corpo para o eu? Em "O ego e o id" (Freud, 1923/1976c, p. 40), o corpo aparece como condição de possibilidade de uma identidade. Freud revela: "o eu é, primeiro e acima de tudo, um eu corporal; não é simplesmente uma entidade de superfície, mas é, ele próprio, a projeção de uma superfície".

0 corpo é um fator que possibilita a distinção entre o id e o eu, a diferenciação dos estímulos externos e internos e, portanto, a separação da realidade externa por meio da percepção de uma identidade. Em 1914, Freud (1914/1976d) revela que o eu não é uma realidade originária: ele é constituído num processo de encontro com dimensões de alteridade.

0 eu ideal refere-se ao narcisismo primário, em que teremos o primeiro investimento sexual em uma unidade, já que, na fase anterior, denominada de autoerotismo, desfilam as pulsões parciais orais, anais e fálicas. Parece-nos pertinente ressaltar que na constituição do eu ideal, está implicada a presença constitutiva do outro, que, na sua sedução e no cuidado, possibilita a percepção do corpo como uma unidade para além da carnalidade.

Assim, o toque do outro no corpo do bebê possibilita a formação do eu. 0 corpo é peça fundamental nesse processo, pois é a sua superfície que delimita e diferencia os estímulos internos e externos. Assim, podemos pensar em uma codependência entre o corpo e o sistema perceptivo, pois este possibilita a delimitação daquele, mas, sem o corpo, o sistema perceptivo não teria espaço para atuação qualitativa. Esse corpo é construído na relação com o outro que a partir do olhar enche de significado o corpo vazio. 0 rosto, possivelmente, representa o primeiro alvo da significação do outro. Os parentes e amigos revelam, ao ver o recém-nascido, que este tem a "cara do pai ou da mãe", não importa, o importante é atribuir um rosto àquela face desprovida de identidade. Na linguagem popular, os bebês são iguais, pois têm a mesma cara. Assim, faz-se necessário oferecer ao bebê a possibilidade de possuir um rosto, um sentido para aquela face, o qual é atribuído pelo outro. A construção do rosto expressa a "caminhada da escuridão para a claridade"1 (Nunes, 1993, p. 35). Podemos pensar que a trajetória de constituição do sujeito inclui os movimentos que revelam um ser sem rosto, que passa a ter o rosto do outro até construir seu próprio rosto. Sua imagem corporal, no entanto, sempre será assombra pela perspectiva da desfiguração total ou parcial, na medida em que essa imagem depende do olhar do outro.

Assim, na pós-modernidade, esse corpo/identidade atinge dimensões plásticas que possibilitam a construção e a reconstrução incessantes. Investir no corpo é um apelo constante da sociedade atual, que exige um corpo saudável e sarado. No mundo contemporâneo, o corpo passa a ser o centro do prazer. Seguindo a trilha de Bauman (1998), que nos revela ser a busca pelo prazer o centro do mundo contemporâneo, podemos pensar que o corpo ocupa o centro do palco da tragédia moderna. Segundo o autor, o homem pós-moderno abre mão da segurança para obter a liberdade de explorar todas as possibilidades de prazer.

\footnotetext{
1 Nessa passagem, a autora discute a origem do termo rosto, anunciando Max Picard como autor dessa afirmação.
} 
Os mal-estares da modernidade provinham de uma espécie de segurança que tolerava uma liberdade pequena demais na busca da felicidade individual. Os mal-estares da pós-modernidade provêm de uma espécie de liberdade de procura do prazer que tolera uma segurança individual pequena demais (Bauman, 1998, p. 10).

Trocamos a busca da felicidade pela busca do prazer. A felicidade, mesmo individual, é um bem coletivo, porque precisa ser vivenciada com o grupo. 0 prazer só necessita de um objeto-coisa que viabilize a experiência íntima e privada. 0 prazer se inscreve no corpo de forma incisiva, o palco do prazer é o corpo. Assim, na pós-modernidade assistimos a uma crescente hipervalorização - provavelmente inédita na história da humanidade - do corpo humano como sede de acontecimentos e como fonte de prazer.

O corpo do idoso possui reduzidas possibilidades de prazer e, nesse sentido, deve ficar escondido ou ser renovado com o auxílio de alta tecnologia. Nesse encontro entre o inevitável do envelhecimento, a tirania do prazer e as novas tecnologias biomédicas figura o espaço da tragédia. Carlson (1997), reconstruindo o raciocínio de Goethe, revela que a tragédia moderna se difere da tragédia grega. A tragédia clássica era regida pelo destino (sollen) e necessidade enquanto a moderna seria regida pela liberdade e vontade (wollen). Essa mudança de sollen para wollen anuncia uma perda no potencial de tragicidade. Segundo Carlson (1997, p. 175), "graças ao sollen, a tragédia se fez grande e poderosa; graças à caprichosa wollen, ela se fez fraca e insignificante, e seu poder dissolveu-se na indulgência e no capricho". As novas tecnologias biomédicas vendem a ilusão de que a decadência do corpo pode ser evitada por meio de intervenções cirúrgicas. 0 envelhecimento da imagem corporal seria uma tragédia que pode ser evitada pela força da vontade. 0 sujeito acredita ser livre para escolher a intervenção técnica mais eficiente contra o envelhecimento de sua imagem corporal. Parece-nos um pacto mefistofélico: venda sua alma para conseguir a imagem de juventude eterna. Pensando na proposta de Erikson (1950/1998) de considerar a velhice a partir do conflito entre sabedoria e desespero, acreditamos que a busca desenfreada por cirurgias plásticas para esconder as marcas do tempo revelam a face do desespero. Sabemos que o sujeito precisa enfrentar grandes desafios na velhice, a saber: manter a integridade do eu, avaliar a vida como uma realização, manter a generatividade, mas orientada à cultura, e avaliar seu percurso com sabedoria. Assim, o idoso enfrenta a luta contra o desespero, o niilismo e a falta de sentido. Dessa maneira, precisamos intervir junto ao idoso e trabalhar a integridade do eu, ou seja, valorizar a vida vivida, conectar o sujeito com seu passado, presente e futuro, construir projetos que possam abraçar a família e a comunidade como campo de cuidado. A limitação corporal não impede a adesão a projetos.

\section{Considerações finais}

Sabemos que a realidade demográfica brasileira encontra-se em acelerada mudança, e que, em um futuro breve, o Brasil deve se encontrar entre os seis países mais populosos do mundo em termos de pessoas idosas (D’Alencar, 2002). Então, é urgente buscar respostas qualitativas para as demandas oriundas desse cenário demográfico e, assim, pensar as condições de vida da população idosa. É preciso se reposicionar diante dos enigmas do tempo e da existência: não há como fugir do envelhecimento do corpo, mas é preciso viver com dignidade. Berlinck (2000) propõe a ideia de envelhescência, ou seja, uma preparação para o envelhecimento que almeja a manutenção da dignidade. 0 autor cunha o conceito a partir de uma comparação com a adolescência, na medida em que nas duas fases da vida ocorrem mudanças físicas e psíquicas. Se o sujeito, por meio de um ato cirúrgico, nega as marcas do envelhecimento no próprio corpo, pode estar apagando sua própria história e confirmando um modelo social que supervaloriza o presente e a juventude. É preciso resistir a esse apelo que nega o fluxo temporal da existência humana.

\section{Referências}

Bauman, Z. (1998). O mal-estar da pós-modernidade. Rio de Janeiro: J. Zahar.

Berlinck, M. T. (2000). A envelhescência. In M. T. Berlinck. Psicopatologia fundamental (pp. 193-198). São Paulo: Escuta.

Bezerra, B. (1989). Subjetividade moderna e o campo da psicanálise. In J. Birman. Freud 50 anos depois (pp. 219-240). Rio de Janeiro: Relume Dumará. 
Carlson, M. (1997). Teorias do teatro: Estudo histórico-crítico, dos gregos à atualidade (G. C. C. Souza Trad.). São Paulo: UNESP.

Courtine, J. J., Corbin, A., \& Vigarello, G. (2008). História do corpo, 3: As mutações do olhar - 0 século $\mathrm{XX}$. Petrópolis: Vozes.

D'Alencar, R. S. (2002). Ensinar a viver, ensinar a envelhecer: Desafios para educação de idosos. Estudos Interdisciplinares Sobre Envelhecimento, 4, 61-83.

Dolto, F. (1984). A imagem inconsciente do corpo. São Paulo: Perspectiva.

Drawin, C. R. (2003). 0 futuro da psicologia: Compromisso ético no pluralismo. In A. M. B. Bock (Org.). Psicologia e o compromisso social (pp. 55-72). São Paulo: Cortez.

Dumont, L. (1985). O individualismo: Uma perspectiva antropológica da ideologia moderna. Rio de Janeiro: Rocco.

Elia, L. (1995). Corpo e sexualidade em Freud e Lacan. Rio de Janeiro: Uapê.

Erikson, E. H. (1998). 0 ciclo de vida completo. Porto Alegre: Artmed.

Foucault, M. (1996). Microfísica do poder. Rio de Janeiro: Graal.

Freud, S. (1895/1976a). Projeto para uma psicologia científica. Edição standard brasileira das obras psicológicas completas de Sigmund Freud (Vol. I, pp. 387-547). Rio de Janeiro: Imago.

Freud, S. (1895/1976b). Estudos sobre a histeria. Edição standard brasileira das obras psicológicas completas de Sigmund Freud (Vol. II, pp. 13-317). Rio de Janeiro: Imago.
Freud, S. (1923/1976c). 0 ego e o id. Edição standard brasileira das obras psicológicas completas de Sigmund Freud (Vol. XIX, pp. 13-86). Rio de Janeiro: Imago.

Freud, S. (1914/1976d). Narcisismo: Uma introdução. Edição standard brasileira das obras psicológicas completas de Sigmund Freud (Vol. XIV, pp. 85-120). Rio de Janeiro: Imago.

Giddens, A. (1997). A vida em uma sociedade pós-tradicional. In A. Giddens, U. Beck \& S. Lah. Modernização reflexiva (pp. 73-133). São Paulo: UNESP.

Lasch, C. (1983). A cultura do narcisismo. Rio de Janeiro: Imago.

Le Breton, D. (2003). Adeus ao corpo: Antropologia e sociedade. Campinas: Papirus.

Mascaro, S. A. (2004). 0 que é velhice. São Paulo: Brasiliense.

Merleau-Ponty, M. (1945/1994). Fenomenologia da percepção (C. Moura, Trad.). São Paulo: M. Fontes.

Neri, A. L. (2001). Desenvolvimento e envelhecimento. Campinas: Papirus.

Nunes, E. L. P. (1993). O outro e o rosto: Problemática da alteridade em Emmanuel Lévinas. Braga: Publicações da Faculdade de Filosofia da U.C.P.

Renaut, A. (1998). 0 indivíduo: Reflexões acerca da filosofia do sujeito. Rio de Janeiro: Difel.

Schopenhauer, A. (1819). 0 mundo como vontade e representação (M. F. Sá Correia, Trad.). Porto: Rés. 